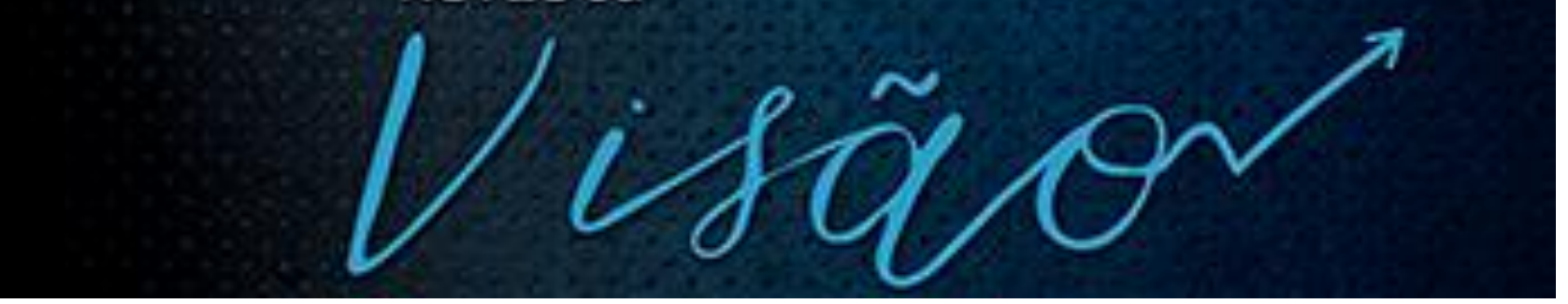

\title{
A ROTATIVIDADE DOCENTE EM UMA INSTITUIÇÃO FEDERAL DE ENSINO:
}

\author{
REALIDADE PREOCUPANTE
}

\section{TEACHER TURNOVER IN A FEDERAL TEACHING INSTITUTION: A WORRYING REALITY}

\author{
Florisvaldo Cunha Cavalcante Junior ${ }^{1}$ \\ https://orcid.org/0000-0003-4850-2854 \\ Tania Nobre Gonçalves Ferreira Amorim² \\ https://orcid.org/0000-0002-9927-4241
}

Recebido em: 10 ago. 2021 Aceito em: 17 fev. 2022

Como citar este artigo: CAVALCANTE JUNIOR, F. C.; AMORIM, T. N. G. F. . A ROTATIVIDADE DOCENTE EM UMA INSTITUIÇÃO FEDERAL DE ENSINO: realidade preocupante. Revista Visão: Gestão Organizacional, Caçador (SC), Brasil, v. 11, n. 1, p. 1-17, 2022. DOI: 10.33362/visao.v11i1.2677. Disponível em: https://periodicos.uniarp.edu.br/index.php/visao/article/view/2677.

Resumo: Em qualquer ambiente organizacional, público ou privado, a rotatividade de pessoal é uma questão que merece um monitoramento contínuo, pois muito elevada ou quase inexistente, pode trazer transtornos para a organização. O objetivo deste estudo é pesquisar a rotatividade de professores em uma Instituição Federal de Ensino (IFE). Do ponto de vista de sua natureza, a pesquisa se classifica como aplicada. No que se refere a abordagem do problema, foi utilizado o método quantitativo. A técnica empregada para a coleta dos dados foi a pesquisa documental. Foram analisadas portarias, atos de nomeações, exonerações e aposentadorias, no período de 2015 a 2019. Identificou-se, que a rotatividade nos últimos cinco anos na IFE é muito alta, considerando que a instituição tem um quadro de 47 docentes e 50 se desligaram do campus nos últimos cinco anos, chegando a 107,44\%. Portanto, sugere-se que a instituição adote, urgentemente, medidas para reduzir tal índice, pois, prejudica os resultados organizacionais, tanto em termos administrativos como em termos acadêmicos, o que é preocupante.

Palavras-Chave: Rotatividade. Professores. Instituição de Ensino.

Abstract: In any organizational environment, whether in a public or private institution, staff turnover is an issue that deserves continuous monitoring, because when it is too high, it brings a series of inconveniences to the organization. The general objective of this

\footnotetext{
${ }^{1}$ Mestre. Instituto Federal da Bahia - IFBA. E-mail: junior.cavalcantte@yahoo.com.br.

2 Doutora. Professora Associada da UFRPE. Universidade Federal Rural de Pernambuco - UFRPE. E-mail: tanobre@gmail.com.
} 
study is to research the turnover of teachers in a federal educational institution. From the point of view of its nature, the research is classified as applied. Regarding the approach to the problem, the quantitative method was used. The technique used for data collection was documentary research. Ordinances, acts of appointments, dismissals and pensions were analyzed in the period from 2015 to 2019. It was identified that the turnover in the last five years at IFE is very high, considering that the institution has a staff of 47 teachers and 50 have left the campus in the last five years, reaching $107.44 \%$. Therefore, it is suggested that the institution urgently adopt measures to reduce this index, as it affects organizational results, both in administrative and academic terms, which is worrying.

Keywords: Turnover. Professors. Educational Institution.

\section{INTRODUÇÃO}

Em qualquer ambiente organizacional, seja em uma instituição pública ou privada, a rotatividade de pessoal é uma questão que merece um monitoramento contínuo, pois quando é elevada demais, pode provocar uma série de transtornos, e ao mesmo tempo, sua quase inexistência também pode afetar a gestão e desempenho organizacional. Autores como Ongori (2007), Robbins et al. (2010), Seidl, Borges-Andrade e Neiva (2019) e Steel e Lounsbury (2009) estudam a rotatividade de pessoal, entendendo-a como uma demissão voluntária solicitada pelo trabalhador, ou mesmo involuntária, quando realizada pela organização, associada à vontade deliberada de trocar de posto de trabalho por iniciativa do trabalhador.

Para Luz e Auler (2015) entre os diversos pontos debatidos na literatura ligada à área de gestão de pessoas, a rotatividade, ou turnover, tem lugar especial, porque afeta gestão e resultados. Esta dinâmica, segundo Nogueira (2006), pode levar a descontinuidade administrativa, caracterizada por políticas, ou, até mesmo organizações que perdem prioridade na agenda, tem seus objetivos alterados ou, no limite, são interrompidas.

As relações entre percepções de sucesso na carreira, bem-estar no trabalho e intenção de rotatividade em trabalhadores do Sudeste do Brasil foi um estudo realizado por Agapito, Polizzi e Siqueira (2015), o qual identificou que as dimensões de bem-estar no trabalho influenciam a intenção de rotatividade dos profissionais, mas a percepção de sucesso na carreira não apresentou elevado impacto.

Dentre outras consequências do desligamento relativas ao indivíduo, está a perda de uma rede de relacionamentos, pela mudança de organização e pelos desafios de aprendizagem no novo serviço, salientados por Chiavenato (2020), o que requer um período de transição, no caso de o funcionário não permanecer ocioso por longo período de tempo. Já Patias et al (2015) destacam que a excessiva rotatividade de pessoal pode causar, além dos efeitos intangíveis, reflexos negativos para a organização, pelo aumento dos custos com treinamento de novos funcionários, horas extras e perdas de produtividade, fatores que contribuem para a elevação 
do custo operacional.

Nesse cenário, evidencia-se a relevância deste estudo, tendo em vista a importância do tema, na eficiência e eficácia da missão das organizações, que precisam monitorar e discutir, continuamente, estratégias de redução de sua rotatividade. "Turnover, então, é um item que necessita atenção nas empresas, não podendo, de forma alguma, ser esquecido pelos gestores" (LUZ; AULER, 2015, p. 1066).

Entretanto, nem sempre o desligamento do servidor público é ocasionado por atritos, por uma proposta de trabalho mais atraente ou ausência de visão de progressão na instituição. Para Azevedo, Lino e Diniz (2019, p. 2) "devido à estabilidade no setor público brasileiro, temse a impressão de que não acontece troca de pessoal nas equipes da camada burocrática no setor público", mas na realidade, não é bem isso que ocorre em muitas instituições. Cavalcante, Lotta e Oliveira (2018), salientam que este é um ponto relevante a ser estudado no âmbito das organizações públicas brasileiras, pois são poucos os estudos nesta esfera.

Nesse contexto, tem-se como problema de pesquisa, responder ao seguinte questionamento: qual a rotatividade de professores em uma instituição federal de ensino federal do interior de Pernambuco? Ante ao exposto, o objetivo geral deste estudo é pesquisar a rotatividade de professores em uma instituição federal de ensino.

\section{REFERENCIAL TEÓRICO}

A Gestão de Pessoas nas organizações atuais é considerada estratégica e muito influencia nos resultados organizacionais, tanto em instituições públicas como privadas, independentemente de seu porte e localização. Pinho, Bastos e Rowe (2015) salientam que gerir pessoas exige não só resolver problemas individuais, coletivos e de relacionamento interpessoal, mas também otimizar custos e ampliar os resultados, tanto para a organização como para as pessoas que nela atuam. Reginaldo, Tartari e Lira (2016) destacam que as pessoas são as grandes responsáveis pelo sucesso organizacional, quando são bem geridas e também podem influenciar sobremaneira o fracasso organizacional quando não são atendidas em suas expectativas e necessidades.

Diante desses desafios, estão os servidores públicos que possuem regulamentação diferenciada dos funcionários da iniciativa privada, e que já em seu ingresso, perpassando pela sua atuação e crescimento na carreira, possuem legislação específica, dependendo da esfera pública em que atuam. Este estudo foca os servidores públicos federais que atuam em Instituições de Ensino Superior - IES, especificamente uma Instituição Federal de Ensino Superior - IFE, em termos da rotatividade dos seus docentes, em um período de 5 anos. 


\section{ROTATIVIDADE DE PESSOAL E ROTATIVIDADE NO SERVIÇO PÚBLICO}

A rotatividade de pessoal, também conhecida por turnover, está relacionada com a saída de funcionários de uma organização. As razões para o desligamento podem ser diversas: os indivíduos podem solicitar a sua demissão por descontentamento com alguma política da empresa, falta de motivação, ou busca de uma melhor colocação profissional, ou a organização pode demitir o funcionário por motivos de inadaptação, produtividade e resultados BUSHMAN; DAI, WANG. (2010); CHEUNG; JACKSON, (2012); ECKERT et al. (2011), MATOS; COLAUTO (2017); OLIVEIRA (2015). Agapito, Polizzi e Siqueira (2015, p. 76) afirmam que a "Rotatividade de pessoal (turnover) corresponde à proporção de empregados que deixam a organização em um determinado período".

A rotatividade traz muitos aspectos negativos, incluindo a perda de funcionários talentosos; erros cometidos por servidores inexperientes; perda de memória organizacional e perda de vínculos pessoais com efeitos negativos no desempenho da organização (Torres, 2015).

Os efeitos, podem ainda ser mais prejudiciais para a administração pública, segundo Ferreira e Neiva (2018) porque os novos servidores são recrutados e selecionados através de entradas caras e demoradas, através de concursos públicos, e que podem levar à interrupção ou redução temporária da prestação de serviços públicos.

Destarte, a Rotatividade de Pessoal tem consequências positivas e negativas, e, deste modo, pode ser favorável ou prejudicial para as organizações na visão de Fausto (2020), Oliveira (2015), Silva (2001) e Siqueira et al., (2012). No Brasil, é identificada uma redução na duração dos vínculos no trabalho e as empresas estão com dificuldades em reter seus funcionários, na visão de Ferreira e Almeida (2015).

Paranaíba (2014) pesquisou a influência de aspectos relacionados às características do trabalho e a satisfação dos trabalhadores, buscando conhecer a intenção de rotatividade de funcionários públicos federais, e identificaram que a satisfação com a remuneração e com promoções são os fatores mais importantes para prever a rotatividade.

Já Diógenes et al. (2016) estudaram funcionários do Ministério da Integração Nacional, e identificaram relações negativas entre intenção de rotatividade e fatores de apoio organizacional como ascensão, promoção e salários, ressaltando a importância da percepção sobre as oportunidades de carreira.

Bastos e Menezes (2010), Scheible e Bastos (2014) e Ferreira e Neiva (2018) identificaram em suas pesquisas que o terreno afetivo, ou comprometimento, é um preditor muito adequado para a intenção de ficar ou não na organização, influenciando diretamente no turnover.

Faz-se relevante ressaltar, que 
O índice de rotatividade equivalente a zero não é habitual na prática e nem seria desejável, pois denotaria um estado de total rigidez e esclerosamento da organização. Porém, um índice de rotatividade da força de trabalho muito elevado também não é desejável, já que reflete um estado de fluidez e entropia da organização, ao não conseguir fixar e assimilar adequadamente seus trabalhadores (SANCHO et al., 2011, p. 444).

O quadro 1, aborda algumas consequências positivas e negativas do turnover para a organização.

Quadro 1 - Consequências positivas e negativas do turnover

\begin{tabular}{|c|c|}
\hline Consequências positivas & Consequências negativas \\
\hline $\begin{array}{l}\text { - Substituição de um funcionário com baixo } \\
\text { desempenho. } \\
\text { - Possibilidade de admitir colaboradores que } \\
\text { tragam para a empresa novos } \\
\text { conhecimentos (ideias, tecnologias, estilos, } \\
\text { inovação etc). } \\
\text { - Redução de comportamentos indesejáveis } \\
\text { como desmotivação, apatia, absenteísmo, } \\
\text { sabotagem, falta de qualidade no trabalho, } \\
\text { etc. } \\
\text { - Diminuição de conflitos entre } \\
\text { colaboradores. }\end{array}$ & $\begin{array}{l}\text { - Quando a empresa substitui um colaborador por outro com } \\
\text { desempenho inferior, impacta negativamente a produção e } \\
\text { nos processos da organização. } \\
\text { - Perdas de funcionários com qualidades e habilidades } \\
\text { especiais ou que ocupam cargos-chave podem ter efeitos } \\
\text { desastrosos por longo período, até o substituto estar } \\
\text { totalmente ambientado. } \\
\text { - "Entrega” para a concorrência de funcionários qualificados. } \\
\text { - Dificuldade nas comunicações e nas relações interpessoais, } \\
\text { na medida em que o colaborador que sai é importante nos } \\
\text { processos de comunicação e fundamental para a coesão da } \\
\text { equipe. } \\
\text { - Pode afetar negativamente o clima organizacional, interferir } \\
\text { na atitude dos funcionários que permanecem na empresa e } \\
\text { estimular uma rotatividade de pessoal adicional, pois alguns } \\
\text { que não estavam à procura de outro emprego, podem } \\
\text { começar a fazê-lo. }\end{array}$ \\
\hline
\end{tabular}

Fonte: baseado em FAUSTO (2013), OLIVEIRA (2015) e SILVA (2001).

Como a organização-objeto de estudo é um órgão público, a questão "recompensa" tem suas limitações, pois a maioria dos benefícios já são fixos e garantidos por lei, entretanto, muito pode ser feito com os processos de "manter pessoas", passando por questões como o melhoramento das condições laborais, monitoramento e acompanhamento do clima organizacional. Afinal, as pessoas são vistas como o principal ativo da organização e influenciam, sobremaneira, a gestão e seus resultados, como salienta Chiavenato (2020).

Portanto, quando uma organização investe e valoriza o seu colaborador, o mesmo irá se sentir importante dentro da organização e tenderá a produzir muito mais, pois se sentirá útil dentro do processo. Cabe ressaltar que, este colaborador, pode passar mais tempo dentro da organização do que na sua própria casa durante sua jornada de trabalho e trajeto à empresa. Assim, a organização deve estar atenta em permitir maior comodidade para o mesmo (SILVA, 2017).

Siqueira et al. (2012) e Siqueira e Alves (2016) constataram poucos estudos sobre 
rotatividade de servidores públicos no Brasil, principalmente, quando realizados em Instituições Federais de Ensino Superior (IFES). Isto pode ser preocupante porque a economia brasileira revela altas taxas de rotatividade de mão de obra, conforme Pereira e Ziero (2013), sendo interessante entender os motivos desta alta rotatividade para adequar políticas públicas ao mercado de trabalho e aos servidores.

O estudo de Siqueira e Alves (2016, p. 104) identificou que a falta de investimento na capacitação e qualificação docente, influencia na retenção, em especial nos campi do interior, o que impossibilita "[...] fazer com que esses se comprometam e se desenvolvam, de maneira apropriada, para contribuir, efetivamente, com o progresso científico e tecnológico da região sudeste de Goiás e também do País". Identificaram também que não era a carreira que levava os docentes a saírem do cargo, mas outros fatores associados a estarem fora da capital, ou mesmo a remoção para outros setores da própria IES em que estão lotados, ou redistribuição para outras instituições de ensino.

As carreiras no serviço público são diversas e dentre elas está a Carreira de Magistério Superior, regida pela Lei ㄲo 8.112/1990 que rege o serviço público federal e a Lei ㄲo 12.772/2012, a qual estrutura a carreira de magistério superior em cinco classes ( $A, B, C, D$ e E) e respectivos níveis de remuneração, regulados pela Medida Provisória no 614/2013. O crescimento na carreira docente se dá por progressão funcional (passagem superior dentro da mesma classe) e promoção (passagem para uma classe subsequente).

O índice de rotatividade adequado para uma organização não é uma unanimidade entre os estudiosos, mas segundo Campos e Malik (2008), precisa estar abaixo de 26\%, para equacionar satisfatoriamente os custos e, acima disso, poderá comprometer a produtividade organizacional e seus resultados. Já os estudos de Julilato (2015) consideram não prejudicial, uma rotatividade de até $15 \%$.

Os estudos de Siqueira e Alves (2016, p. 104) com docentes de uma IFE, indicou que 90\% deles saíram da instituição em cerca de 5 anos, salientando que o estudo tratava de uma IFE do interior do estado e que "todos os professores desligados foram para grandes centros, provavelmente, em busca de melhores oportunidades de qualificação, já que 77,78\% haviam concluído apenas o mestrado".

REMOÇÃO/REDISTRIBUIÇÃO

Segundo a Lei 8.112 de 11 de dezembro de 1990, art. 36:

Remoção é o deslocamento do servidor, a pedido ou de ofício, no âmbito do mesmo quadro, com ou sem mudança de sede.

Parágrafo único. Para fins do disposto neste artigo, entende-se por modalidades de remoção:

I - De ofício, no interesse da Administração;

II - A pedido, a critério da Administração;

III - A pedido, para outra localidade, independentemente do interesse da 
Administração:

a) para acompanhar cônjuge ou companheiro, também servidor público civil ou militar, de qualquer dos Poderes da União, dos Estados, do Distrito Federal e dos Municípios, que foi deslocado no interesse da Administração;

b) por motivo de saúde do servidor, cônjuge, companheiro ou dependente que viva às suas expensas e conste do seu assentamento funcional, condicionada à comprovação por junta médica oficial;

c) em virtude de processo seletivo promovido, na hipótese em que o número de interessados for superior ao número de vagas, de acordo com normas preestabelecidas pelo órgão ou entidade em que aqueles estejam lotados.

A figura 1, ilustra um exemplo de processo de remoção.

Figura 1 - Fluxo da Remoção

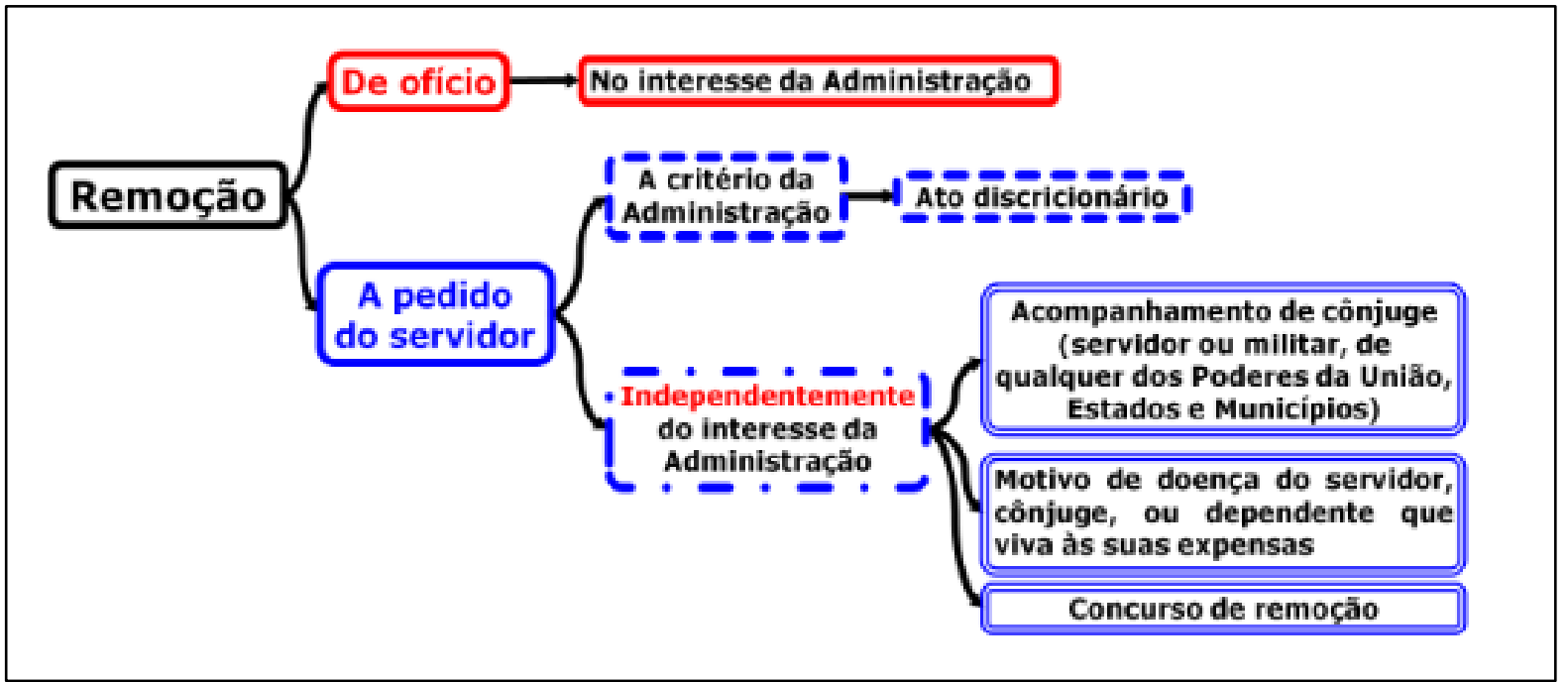

Fonte: Borges (2020)

O interesse da Administração é indispensável, posto que para concretização da remoção, em regra, faz-se necessária a troca de um código de vaga do mesmo cargo entre o Campus de destino e o Campus de origem, a fim de viabilizar a nomeação de outro servidor para suprir a ausência do removido (IFTM, 2020).

O Art. 37, da mesma lei, aborda que a Redistribuição é o deslocamento de cargo de provimento efetivo, ocupado ou vago no âmbito do quadro geral de pessoal, para outro órgão ou entidade do mesmo Poder, com prévia apreciação do órgão central do SIPEC, observados os seguintes preceitos:

I - Interesse da administração;

II - Equivalência de vencimentos;

III - Manutenção da essência das atribuições do cargo;

IV - Vinculação entre os graus de responsabilidade e complexidade das atividades;

V - Mesmo nível de escolaridade, especialidade ou habilitação profissional;

VI - Compatibilidade entre as atribuições do cargo e as finalidades institucionais do órgão ou entidade.

$\S 1$ 10 A redistribuição ocorrerá ex-ofício para ajustamento de lotação e da força de trabalho às necessidades dos serviços, inclusive nos casos de reorganização, extinção 
ou criação de órgão ou entidade.

$\S 2$ ㅇ A redistribuição de cargos efetivos vagos se dará mediante ato conjunto entre o órgão central do SIPEC e os órgãos e entidades da Administração Pública Federal envolvidos.

§ 3은 Nos casos de reorganização ou extinção de órgão ou entidade, extinto o cargo ou declarada sua desnecessidade no órgão ou entidade, o servidor estável que não for redistribuído será colocado em disponibilidade, até seu aproveitamento.

A figura 2, apresenta a diferença entre Remoção e Redistribuição.

Figura 2 - Diferença entre Remoção e Redistribuição

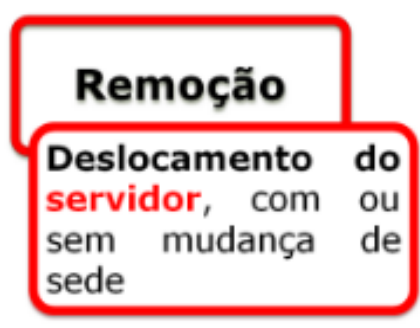

Um exemplo de deslocamento de cargo desocupado é quando se oferece um código de vaga de determinado cargo como contrapartida para a redistribuição de um servidor ocupante do mesmo cargo, situação que possibilita a nomeação de candidatos classificados em concursos ou a realização de certames. Já um exemplo de deslocamento de cargo ocupado é a redistribuição de um servidor, ocupante de determinado código de vaga/cargo, para outra Instituição (IFTM, 2020).

O estudo de Recktenwald, Paula, Carvalho (2017), constatou que a rebeldia e a oposição à hierarquia são características marcantes da rotatividade de pessoal, tanto como o individualismo. Constatou, também, que um dos principais fatores de motivação à rotatividade em todas as gerações está relacionado ao salário e sua importância na sustentação da família do trabalhador.

\section{PROCEDIMENTOS METOLÓGICOS}

A presente pesquisa tem como objetivo pesquisar a rotatividade de professores em uma instituição federal de ensino superior. Do ponto de vista de sua natureza, a pesquisa se classifica como aplicada. Para Kauark, Manhães e Medeiros (2010, p. 26) este tipo de pesquisa "objetiva gerar conhecimentos para aplicação prática, dirigida à solução de problemas específicos. Envolve verdades e interesses locais".

No que se refere a abordagem do problema, foi utilizado o método quantitativo, com propósito exploratório. Para Kauark, Manhães, Medeiros (2010, p. 27) a pesquisa quantitativa 
"lida com fatos, tudo aquilo que pode se tornar objetivo através da observação sistemática; evento bem especificado, delimitado e mensurável".

Beuren et. al. (2003, p. 80) destacam que "por meio do estudo exploratório, busca-se conhecer com maior profundidade o assunto, de modo a torná-lo mais claro ou construir questões importantes para a conclusão da pesquisa". Cervo, Bervian e Silva (2007), complementam que "a pesquisa exploratória realiza descrições precisas da situação e quer descobrir as relações existentes entre seus elementos componentes".

A técnica empregada para a coleta dos dados foi a pesquisa documental. A pesquisa documental é muito parecida com a bibliográfica, contudo, a diferença está na natureza das fontes, pois esta forma vale-se de materiais que não receberam ainda um tratamento analítico (GIL, 2008).

Diante disso, foi estudado o quadro docente de uma Instituição Federal de Ensino do Interior de Pernambuco, em funcionamento há menos de 10 anos. Foram analisados diversos documentos, tais como, portarias, atos de nomeações, exonerações e aposentadorias, no período de 2015 a 2019, disponíveis no site da instituição e no Diário Oficial da União (DOU). Até 31/12/2019, a instituição possuía um total de 47 docentes efetivos em seu quadro.

\section{ANÁLISE E DISCUSSÃO DOS RESULTADOS}

Os dados coletados no DOU e Portarias, disponíveis no site da Instituição Federal de Ensino, estão apresentados, nesta seção, a iniciar, pela Tabela 1, que apresenta o Total de Admitidos e Desligados nos últimos 5 anos.

Tabela 1 - Relação de Admitidos e Desligados nos últimos 5 anos

\begin{tabular}{l|l|l|l|l|l|l}
\hline TIPO & 2015 & 2016 & 2017 & 2018 & 2019 & TOTAL \\
\hline Admitidos & 06 & 20 & 06 & 05 & 14 & 51 \\
\hline Desligados & 04 & 13 & 07 & 09 & 17 & 50 \\
\hline
\end{tabular}

Fonte: Elaborado pelos autores (2020)

Considerando que o total de docentes efetivos da instituição, até a data de encerramento da pesquisa, é de 47, a rotatividade identificada é considerada muito alta, com mais de $100 \%$ do quadro tendo sido renovado, nos últimos cinco anos. Observa-se, que essa rotatividade tem aumentado no decorrer dos anos, atingindo seu máximo no ano de 2019.

Segundo Fortes (2020), o cálculo de turnover ou de rotatividade de pessoal é o que diz respeito à movimentação de pessoas, ou seja, as entradas e saídas que alteram o quadro de funcionários da organização, em determinado período. Sua fórmula é a seguinte:

Turnover geral $=([$ Admitidos no período + Desligados no período $] / 2) /$ total de funcionários x100. 
Turnover geral $=([51+50] / 2=50,5$.

Turnover geral $=50,5 / 47=1,07$.

Turnover geral $=1,07 \times 100=107,44$.

Isso indica que a taxa de turnover geral da IFE estudada foi de 107,44\%. Normalmente a meta das organizações é que esse percentual esteja entre $10 \%$ e $25 \%$, mas Julilato (2015) considera não prejudicial, uma taxa de turnover até 15\%. Já Campos e Malik (2008), defendem que precisa estar abaixo de $26 \%$, como visto anteriormente.

Siqueira e Alves (2016) em seu estudo sobre o turnover, também com docentes de uma IFE no estado de Goiás, indicou que 90\% deles saíram da instituição em cerca de 5 anos, salientando-se que o estudo tratava de uma IFE do interior do estado, como a que foi foco neste estudo, o que vem confirmar o que foi identificado na IFE estudada em Pernambuco.

Para renovar seu quadro, a instituição recebe servidores em cinco diferentes modalidades, conforme apresentado na Tabela 2.

Tabela 2 - Tipos de admissões

\begin{tabular}{l|l|l|l|l|l|l}
\hline TIPO & 2015 & 2016 & 2017 & 2018 & 2019 & TOTAL \\
\hline $\begin{array}{l}\text { Aprovação em Concurso Público } \\
\text { realizado pela Instituição }\end{array}$ & 04 & 19 & 05 & 01 & 09 & $\begin{array}{l}38 \\
(74,52 \%)\end{array}$ \\
\hline $\begin{array}{l}\text { Aproveitamento de Concurso Público } \\
\text { de Outra Instituição }\end{array}$ & 01 & - & - & 02 & 02 & $\begin{array}{l}05 \\
(9,80 \%)\end{array}$ \\
\hline Remoção Interna & - & - & - & 01 & - & $\begin{array}{l}01 \\
(1,96 \%)\end{array}$ \\
\hline Redistribuição sem Permuta & - & - & - & 01 & 02 & $\begin{array}{l}03 \\
(5,88 \%)\end{array}$ \\
\hline Redistribuição com Permuta & 01 & 01 & 01 & - & 01 & $\begin{array}{l}04 \\
(7,84 \%)\end{array}$ \\
\hline TOTAL & $\begin{array}{l}06 \\
(11,76 \%)\end{array}$ & $\begin{array}{l}20 \\
(39,21 \%)\end{array}$ & $\begin{array}{l}06 \\
(11,76 \%)\end{array}$ & $\begin{array}{l}5 \\
(9,80 \%)\end{array}$ & $\begin{array}{l}14 \\
(27,45 \%)\end{array}$ & $\begin{array}{l}51 \\
(100 \%)\end{array}$ \\
\hline
\end{tabular}

Fonte: Elaborado pelos autores (2020)

Os Concursos Públicos realizados pela instituição representam o maior número de admissões (74,52\%), seguido do Aproveitamento de Concursos de outras instituições $(9,80 \%)$ e da Redistribuição com Permuta (7,84\%). Um fato que chama atenção é que apenas um servidor solicitou Remoção Interna para o campus nos últimos cinco anos, o que evidencia, um cenário atípico, no tocante, talvez, à uma certa falta de interesse pelo campus em que a IFE estudada se encontra.

Vale ressaltar, que segundo os documentos estudados, a instituição só realiza aproveitamento de Concurso Público de outra instituição, quando não possui banco de aprovados em concurso próprio, assim como, só realiza Redistribuição sem Permuta, quando seu concurso vigente esgota todas as vagas. 
Em resumo, a ordem de admissão, pela legislação vigente na instituição é a seguinte: primeiro são realizadas as Remoções Internas; as vagas remanescentes são destinadas aos aprovados no Concurso Público da instituição. Na ausência, aí sim, entram as Redistribuições sem permuta e os aproveitamentos de listas de outros concursos públicos federais, como autoriza a legislação.

Importante ressaltar, ainda, que as Redistribuições com Permuta não fazem parte dessa norma, visto que, são trocas entre professores, e isso não significa surgimento de nova vaga. Por isso, são realizadas, mesmo havendo Concurso Público vigente nas instituições.

Os desligamentos da instituição estudada, ocorrem em sete modalidades, conforme elencado na Tabela 3.

Tabela 3 - Tipo de desligamentos

\begin{tabular}{|c|c|c|c|c|c|c|}
\hline TIPO & 2015 & 2016 & 2017 & 2018 & 2019 & TOTAL \\
\hline Aposentadoria & - & - & 01 & - & - & $\begin{array}{l}01 \\
(2 \%)\end{array}$ \\
\hline Aprovação em outro Concurso Público & - & - & 01 & 01 & 01 & $\begin{array}{l}03 \\
(6 \%)\end{array}$ \\
\hline Exoneração & - & 01 & - & - & - & $\begin{array}{l}01 \\
(2 \%)\end{array}$ \\
\hline Exoneração (a pedido) & - & - & 01 & - & - & $\begin{array}{l}01 \\
(2 \%)\end{array}$ \\
\hline Remoção Interna & 04 & 08 & 02 & 06 & 08 & $\begin{array}{l}28 \\
(56 \%)\end{array}$ \\
\hline Redistribuição sem Permuta & - & 02 & 01 & 02 & 07 & $\begin{array}{l}12 \\
(24 \%)\end{array}$ \\
\hline Redistribuição com Permuta & - & 02 & 01 & - & 01 & $\begin{array}{l}04 \\
(8 \%)\end{array}$ \\
\hline TOTAL & $04(8 \%)$ & $13(26 \%)$ & $\begin{array}{l}07 \\
(14 \%)\end{array}$ & $\begin{array}{l}09 \\
(18 \%)\end{array}$ & $\begin{array}{l}17 \\
(34 \%)\end{array}$ & $\begin{array}{l}50 \\
(100 \%)\end{array}$ \\
\hline
\end{tabular}

Fonte: Elaborado pelos autores (2020)

A Remoção Interna, é a modalidade que registra o maior número de saídas da instituição (56\%), seguido da Redistribuição sem Permuta (24\%) e Redistribuição com Permuta (8\%). A Remoção Interna é a modalidade mais recorrente porque são lançados periodicamente os editais de remoção, sempre que surge uma nova vaga na instituição. Não exige um tempo mínimo de efetivo exercício no campus e a classificação é feita pelo tempo de atuação, o que torna o processo mais simples e mais acessível aos docentes.

Por outro lado, as redistribuições costumam ter regras mais rígidas, a exemplo da exigência do cumprimento do estágio probatório na instituição de origem (36 meses); não pode ser realizada 90 dias antes e depois do pleito; o candidato da instituição de origem não pode ter escolaridade inferior ao da instituição cedente, entre outros requisitos, que variam de instituição para instituição. 
A Tabela 4, apresenta áreas com o maior percentual de rotatividade (desligamentos), identificadas no estudo.

Tabela 4 - Áreas com o maior percentual de rotatividade (desligamentos)

\begin{tabular}{l|l|l|l|l|l|l}
\hline TIPO & 2015 & 2016 & 2017 & 2018 & 2019 & TOTAL \\
\hline Administração & - & 01 & 01 & - & - & $02(4 \%)$ \\
\hline Agronomia & - & 01 & - & 01 & 02 & $04(8 \%)$ \\
\hline Agroindústria & 01 & - & - & - & - & $01(2 \%)$ \\
\hline Alimentos & - & - & 03 & 01 & - & $04(8 \%)$ \\
\hline Biologia & - & 01 & - & - & - & $01(2 \%)$ \\
\hline Educação Física & - & 01 & - & - & - & $01(2 \%)$ \\
\hline Física & - & 01 & - & 01 & 02 & $04(8 \%)$ \\
\hline História & - & - & - & 01 & - & $01(2 \%)$ \\
\hline Inglês & - & - & - & 01 & 02 & $03(6 \%)$ \\
\hline Informática & - & 04 & 02 & - & 04 & $10(20 \%)$ \\
\hline Matemática & 01 & 02 & - & - & 03 & $06(12 \%)$ \\
\hline Música & 01 & 01 & - & 01 & 01 & $04(8 \%)$ \\
\hline Pedagogia & - & - & - & 01 & - & $01(2 \%)$ \\
\hline Português & 01 & - & 01 & 01 & - & $03(6 \%)$ \\
\hline Química & - & 01 & - & 01 & 02 & $04(8 \%)$ \\
\hline Sociologia & - & - & - & - & 01 & $01(2 \%)$ \\
\hline TOTAL & 04 & 13 & 07 & 09 & 17 & $50(100 \%)$ \\
\hline Fonte: Elaborado & - & & & & \\
\hline
\end{tabular}

Fonte: Elaborado pelos autores (2020)

Entre as áreas que apresentam maior rotatividade estão: Informática (20\%), Matemática (12\%) e Agronomia, Alimentos, Física, Música e Química (8\%). Provavelmente, a limitação tecnológica vivenciada em algumas cidades do interior, somadas à distância do núcleo familiar, sejam os principais fatores de rotatividade da área de informática.

Essa movimentação ocorre, provavelmente, devido à questão familiar, em que praticamente todos os docentes almejam transferência para as cidades nas quais mantém núcleo familiar somada a vasta oferta de vagas, principalmente nas áreas de Matemática, Física e Química, o que talvez possa explicar tal fenômeno. Estudos como os de Siqueira e Alves (2016) também indicaram que grande parte das movimentações dos docentes são voltadas ao retorno para a capital, ponto de origem dos mesmos.

Embora, entenda-se os motivos de tais movimentações, a rotatividade de pessoal muito alta, como observada neste estudo, acarreta em prejuízos imensuráveis para a gestão, corpo administrativo, como também destacam Patias et al (2015), e principalmente para os discentes, por precisarem se adaptar, às vezes em um mesmo semestre, a novas metodologias de trabalho, o que pode comprometer sobremaneira o processo de ensino-aprendizagem.

Reginaldo, Tartari e Lira (2016) destacam também que as pessoas são as grandes 
responsáveis pelo sucesso ou fracasso organizacional, e quando não são atendidas em suas expectativas e necessidades, buscam novas alternativas de trabalho, o que pôde ser também identificado neste estudo.

\section{CONSIDERAÇÕES FINAIS}

O objetivo geral deste estudo foi pesquisar a rotatividade de professores em uma instituição federal de ensino no interior de Pernambuco, buscando identificar seu índice e possíveis consequências para os resultados organizacionais.

Identificou-se, que a rotatividade da IFE estudada é muito alta, dentro do intervalo de cinco anos, pois ao se calcular o turnover, o resultado encontrado foi muito acima do recomendado pela literatura, chegando a 107,44\%. Isto pode acarretar inúmeros problemas de cunho administrativo e acadêmico para a IFE. Percebeu-se, ainda que, a rotatividade de pessoal vem aumentando ao longo dos anos e, no ano de 2019, atingiu 36,17\% do quadro total de professores. Ações na área de Gestão de Pessoas precisam ser planejadas com o intuito de reduzir a rotatividade docente.

Constatou-se também que a principal forma de desligamento identificada na IFE é a remoção interna, talvez por ser mais simples e ocorrer periodicamente. Verificou-se, também, que as áreas com maior rotatividade são as de Informática e Matemática.

Os docentes da IFE estudada estão acompanhando movimentos muito frequentes em outras organizações brasileiras, em que os funcionários e servidores estão trocando a organização com muita facilidade, talvez pelas várias ofertas que a própria União disponibiliza, ou até mesmo, por insatisfação com o perfil ou localização da instituição. Mas quando são analisados os reais motivos, consegue-se observar que nem sempre essa troca tem uma diferença tão considerável para o servidor. Isto talvez sugira que o problema não seja a carreira docente, mas há a possibilidade de que características específicas da IFE como gestão e localização, estejam influenciando a elevada rotatividade identificada. Então, faz-se mister que a IFE busque identificar as causas da elevada rotatividade de seus docentes.

Apesar das limitações deste estudo de caso, as quais não permitem generalizações, os achados deste estudo podem ser considerados como sugestivos para outras realidades semelhantes. Então, pode-se utilizar a ferramenta desta pesquisa para se analisar o quadro de Pessoal Administrativo e de docentes de Universidades Federais de Interior, bem como, para pesquisar junto aos docentes as reais motivações para o desligamento de seus campi, analisando as devidas consequências para a instituição de ensino e para eles mesmos. 


\section{REFERÊNCIAS}

AGAPITO, P. R.; POLIZZI, A. P. F.; SIQUEIRA, M. M. M. Bem-estar no trabalho e percepção de sucesso na carreira como antecedentes de intenção de rotatividade. Revista de Administração Mackenzie, v. 16, n. 6, Edição Especial, p. 71-93, 2015.

AZEVEDO, R. R.; LINO, A. F.; DINIZ, J. A. Efeitos da Rotatividade de Pessoal sobre Práticas das Equipes de Contabilidade em Municípios. Revista de Contabilidade e Organizações, v. 13, n. 2, p. 1-14, 2019.

BEUREN, I. M. (organizadora). Como elaborar trabalhos monográficos em contabilidade: Teoria e Prática. São Paulo: Atlas, 2003.

BORGES, C. Curso Avançado de Direito Administrativo. Disponível em: <https://docplayer.com.br/6636121-Curso-avancado-de-direito-administrativo-emexercicios-profo-cyonil-borges.html>. Acesso em 01 abr. 2020.

BRASIL. Diário Oficial da União. Secretaria-Geral da Presidência da República. Imprensa Nacional. Seção 2: Atos de Pessoal. Disponível em: <http://www.in.gov.br/web/guest/inicio>. Acesso em 01 abr. 2020.

BRASIL. Lei 8.112, de 11 de dezembro de 1990. Dispõe sobre o regime jurídico dos servidores públicos civis da União, das autarquias e das fundações públicas federais. Disponível em: <http://www.planalto.gov.br/ccivil_03/leis//8112cons.htm>. Acesso em 01 abr. 2020.

BRASIL. Lei n. 12.772, de 28 de dezembro de 2012. Dispõe sobre a estruturação do Plano de Carreiras e Cargos de Magistério Federal; sobre a Carreira do Magistério Superior. Disponível em Disponível em: <htp://www.planalto. gov.br/ccivil_03/_ato2011-2014/2012/lei/l12772. htm>. Acesso em: 04 abr, 2020.

BRASIL. Medida Provisória n. 614, de 14 de maio de 2013. Que dispõe sobre a estruturação do Plano de Carreiras e Cargos de Magistério Federal. Disponível em:

<htp://www.planalto.gov.br/ccivil_03/_ato2011-2014/2013/Mpv/mpv614. htm\#art1>. Acesso em: 04 abr, 2020.

BUSHMAN, R.; DAI, Z.; WANG, X. Risk and CEO turnover. Journal of Financial Economics, v. 96, n. 3, p. 381-398, 2010.

CAMPOS, C. V. de A.; MALIK, A. M. Satisfação no trabalho e rotatividade dos médicos do Programa de Saúde da Família. Revista de Administração Pública - RAP, Rio de Janeiro, v. 42, n. 2, p. 347-368, mar./abr. 2008.

CERVO, A. L.; BERVIAN, P. A.; SILVA, R. da. Metodologia científica. 6. Ed., São Paulo: Prentice Hall, 2007.

CHIAVENATO, I. Gestão de Pessoas: O novo papel do talento humano. 5. Ed., São Paulo: Atlas, 2020. 
CHEUNG, W. J.; JACKSON, A. B. Chief Executive Officer departures and market uncertainty. Australian Journal of Management, v. 38, n. 2, 279-310, 2012.

DIÓGENES, L.; PASCHOAL, T.; NEIVA, E.R.; MENESES, P. P. M. Intenção de rotatividade e percepção de suporte organizacional em um órgão público federal. Revista do Serviço Público, v. 67, n. 2., 2016.

ECKERT, A.; MECCA, M. S.; DENICOL, M. S. G. M.; GIACOMET, M. O. As motivações e os reflexos do turnover em termos contábeis e econômicos numa entidade sem fins lucrativos do município gaúcho de Caxias do Sul. XIII CONVENÇÃO DE CONTABILIDADE DO RIO GRANDE DO SUL. Anais... Caxias do Sul, 2011.

FAUSTO, F. As consequências da Rotatividade de Pessoal. GP Portal. Disponível em: <http://www.gpportal.com.br/2013/08/as-consequencias-da-rotatividade-de.html>. Acesso em 01 abr. 2020.

FERREIRA, P. C.; NEIVA, E. R. Antecedents of Turnover in Federal Public Administration. Revista de Administração, v. 53, n. 3, p. 366-384, 2018.

FORTES TECNOLOGIA. Cálculo de turnover: como saber se sua empresa está indo bem? 2019. Disponível em: < https://blog.fortestecnologia.com.br/calculo-de-turnover/> . Acesso em 01 abr. 2020.

GIL, A.C. Métodos e técnicas de pesquisa social. 6 ed. São Paulo: Atlas, 220p. 2008.

IFTM. Remoção e Redistribuição: Entenda quando é possível a transferência de servidores entre unidades da mesma instituição ou entre instituições diferentes. Disponível em:

<https://iftm.edu.br/dgpinfo/informativos/remocao-redistribuicao.html. . Acesso em 01 abr. 2020.

KAUARK, F. S.; MANHÃES, F. C.; MEDEIROS, C. H.. Metodologia da pesquisa: um guia prático. Itabuna: Via Litterarum Editora, 2010.

LUZ, M.; AULER, D. P. Rotatividade de pessoal em prestadores de serviços: um estudo de caso em uma associação desportiva. Revista Eletrônica Gestão e Serviços, v. 6, n. 1, p. 1058-1083, 2015.

MATOS, R. M.; COLAUTO, R. D. Justificativas do Turnover de Ceos: Estudo em Companhias Brasileiras Investidas por Fundos de Pensão. Revista de Contabilidade e Organizações, v. 11, n. 30, p. 24-35, 2017.

PARANAÍBA, N. F. Satisfação no trabalho e intenção de rotatividade de servidores das carreiras de uma autarquia federal. In: Camões, M.R.S.; Fonseca, D.R.; Porto (Eds), Estudos Em Gestão de Pessoas No Serviço Público, ENAP, Brasília, 2014.

PATIAS, T. Z.; WITTMANN, M. L.; LISZBINSKI, B. B.; BALESTRERI, A. S.; COSTA, C. F. Custos da rotatividade de pessoal: evidências no setor de supermercados. RACE: Revista de Administração, Contabilidade e Economia, v. 14, n. 1, p. 143-170, 2015. 
NOGUEIRA, F. A. Continuidade e Descontinuidade Administrativa em Governos Locais: Fatores que sustentam a ação pública ao longo dos anos. Dissertação de Mestrado. São Paulo: Fundação Getúlio Vargas. 2006.

ONGORI, H. A review of the literature on employee turnover. African Journal of Business Management, v. 1, n. 2, p. 49-54, 2007.

OLIVEIRA, T. F. Rotatividade De Pessoal - Turnover. RH Portal. 2015. Disponível em: $<$ https://www.rhportal.com.br/artigos-rh/rotatividade-de-pessoal-turnover/>. Acesso em 01 abr. 2020.

PEREIRA, D. A.; ZIERO, J. G. Uma nota sobre a rotatividade da mão-de-obra do setor privado brasileiro. Revista de Economia e Administração. v. 12, n. 1, p. 132-148. 2013.

PINHO, A. P. M.; BASTOS, A. V. B.; ROWE, D. E. O. Diferentes vínculos organizacionais: explorando concepções, fatores organizacionais antecedentes e práticas de gestão. Organizações \& Sociedade. v. 22, n. 75, p. 659-680, out./dez., 2015.

RECKTENWALD, A.; PAULA, G.; CARVALHO, L. Conflito de Gerações e o Impacto na Rotatividade de Pessoal no Setor de Embalagens de Empresa do Ramo Lácteo. Revista de Carreiras e Pessoas, v. 7, n. 2, p. 496-510, 2017.

REGINALDO, T; TARTARI, J. S.; LIRA, W. J. Imagens arquetípicas na gestão de pessoas. Navus Revista de Gestão e Tecnologia, v. 6, n. 1, p. 06-16, jan./mar., 2016.

ROBBINS, S. P.; JUDGE, T. A.; SOBRAL, F. Comportamento organizacional. Teoria e prática no contexto brasileiro. 14. ed., São Paulo: Pearson Prentice Hall, 2010.

SANCHO, Leyla Gomes; CARMO, Juliana Martins do; SANCHO, Rafael Gomes; BAHIA, Ligia. Rotatividade na força de trabalho da rede municipal de saúde de Belo Horizonte, Minas Gerais: um estudo de caso. Trabalho, Educação e Saúde, Rio de Janeiro, v. 9, n. 3, p. 431- 447, 2011.

STEEL, R. P.; LOUNSBURY, J. W. Turnover process models: Review and synthesis of a conceptual literature. Human Resource Management Review, v. 19, p. 271-282, 2009.

SEIDL, J.; BORGES-ANDRADE, J. E.; NEIVA, E. R. Rotatividade: Análise de Vinte Anos da Produção Científica Brasileira. Revista de Administração FACES Journal, v. 18, n. 2, p. 44-64, 2019.

SIQUEIRA, W. R.; ALVES, L. C. F. Rotatividade de Professores Universitários: o Caso de um Campus Fora da Sede. Revista de Administração, Contabilidade e Economia da FUNDACE, v. 7, n. 2, p. 94-107, 2016.

SIQUEIRA, W. R.; TAVARES, R. F.; BUENO, M.; BA, S. A. C. Rotatividade de servidores públicos: estudo realizado em um campus universitário do interior de Goiás. In: ENCONTRO NACIONAL DOS CURSOS DE GRADUAÇÃO EM ADMINISTRAÇÃO - ENANGRAD, 2012, Bento Gonçalves. Anais... Rio de Janeiro: ANGRAD, 2012. 
SILVA, C. A importância da Gestão de Pessoas para os colaboradores. 2017. Administradores. Disponível em: < https://administradores.com.br/artigos/a-importancia-da-gestao-depessoas-para-as-colaboradores>. Acesso em 01 abr. 2020.

SILVA, Glenio Luiz da Rosa e. Controle do turnover: como prevenir e demitir com responsabilidade. Rio de Janeiro: Qualitymark, 2001.

TORRES, R. V. B. S. Rotatividade no Poder Executivo Federal: uma análise das intenções de sair e de permanecer dos servidores comissionados. Dissertação (mestrado), Universidade de Brasília, 2015. 